\title{
A fractional perspective to the bond graph modelling of world economies
}

\author{
J. A. Tenreiro Machado - Maria Eugénia Mata
}

\begin{abstract}
Inspired in dynamic systems theory and Brewer's contributions to apply it to economics, this paper establishes a bond graph model. Two main variables, a set of inter-connectivities based on nodes and links (bonds) and a fractional order dynamical perspective, prove to be a good macro-economic representation of countries' potential performance in nowadays globalization. The estimations based on time series for 50 countries throughout the last 50 decades confirm the accuracy of the model and the importance of scale for economic performance.
\end{abstract}

Keywords Fractional calculus - Bond graphs · Economy $\cdot$ Modelling $\cdot$ Dynamics

\section{Introduction}

In 1695 Gottfried Leibniz conceived the derivative of order $1 / 2$. This idea leads to the area usually known as 'Fractional Calculus' (FC) and represents the general- ization of the operations of integration and differentiation up to real or complex orders $[34,46,49,52,55,57]$. During the last decades researchers verified that fractional models capture memory effects of natural and artificial phenomena, while classical integer models reveal limitations when describing those properties $[6,29,44,65,71]$. This state of affairs has motivated an intensive research towards new areas of application of the novel concepts, and we verify a sustained growth in the number of publications involving this mathematical tool $[42,43]$.

Bond graphs (BG) were created by Henry Paynter at MIT during the fifties [53]. Paynter noted that distinct 'domains', such as electrical, mechanical and fluid systems, were modelled by equations of the same form. These systems are nowadays commonly called 'analogous'. The BG method is a graphical modelling tool based on the energy transfer rate within the system. The constitutive elements are interconnected by 'bonds' that specify the power transfer between them. Therefore, 'power' (the time rate of energy transfer) between the distinct components is the main concept supporting the description of physical systems. Since then, the BG theory has been developed by many researchers $[7,8,21,23,24,33,48,67,68,74]$ that extended the technique to power hydraulics, mechatronics, thermo-dynamics and, more recently, to nonphysical systems like micro-economy [10-12,76] and architecture $[36,69,70]$. The BG graphical representation and the derivation of system equations is system- 
atic and can be algorithmized by existing software (e.g. 20-sim, Camp-G, ENPORT and others).

Well-succeeded countries have been studied as cases of exceptionalism in economic history. The UK dominance over the world in the nineteenth century was exceptional because of pioneering the steam-engine industrialization [20]. The American hegemony in the twentieth century was a case of exceptionalism because of exceptional resource endowments [3,54]. Other successful countries were interpreted as cases of exceptional replication opportunities [1].

According to these views, technological development did not command growth, because its adoption may be explained by the opportunity cost of labour force wages [4]. Large literature on the causes for growth and stagnation elects industrial productivity and wages as the secret for new-technology adoption [51,60]: most regions 'could not have industrialized by following American policies since their wages were so low and their energy costs so high that the modern technology that was cost effective in Britain and the USA would not have paid in their circumstances' [4]. At the same time contradictory interpretations are available on large territories. On the one side, economic policy is a relevant driver to growth, it is said [50]. (For example, 'The development of Egypt and India required more draconian state intervention than a protective tariff, mass education, and infrastructure investment' [4]). On the other side, they were victims of mother-country economies and could not develop appropriate institutional environments for economic growth, according to other views [2].

Among so large and diversified literature, scale has not deserved enough attention, although the generalequilibrium models perspective is also available [66]. This paper prefers to approach economic growth according to bond graphs modelling theories to elect a few number of variables expressing scale and observe the economic growth of 50 nations throughout the last 50 years, the period for which reliable data are available (http://data.worldbank.org/). Exceptionalism may become interpreted as a much less exceptional view.

Having these ideas in mind this paper is organized as follows. Section 2 presents the fundamental aspects of bond graph theory. Section 3 is a literature review of BG application to economic systems and a general presentation of this paper model. The discussion of results is presented in Sect. 4, and Conclusions follow up in Sect. 5.

\section{Bond graphs: fundamentals}

The fundamental idea of a BG is that power $P$ is transmitted between connected components by a combination of 'effort' and 'flow' so that $P(t)=e(t) f(t)$, where $t$ is time. In general the two variables are called 'generalized effort' and 'generalized flow'. The power interconnection between elements is denoted by 'bonds'. Table 1 presents examples of different domains and the corresponding effort and flow variables. We should note that the assignment for variables $e$ and $f$ can be rotated. For example, some authors switch the Force and Velocity pair in mechanical systems. The resulting changes do not preclude neither the model validity nor its generality. In some domains the product of effort and flow does not lead to power, because extending the BG method to new applications requires the generalization of the concept of power.

The effort and flow signals are carried by the single power bond and represented in Fig. 1. The direction of the half-arrow indicates the positive direction of power transport between elements A and B. Therefore, in Fig. 1, power transfer from left to right is considered positive and negative otherwise.

The fundamental variables are effort $e$ and flow $f$, but we need to keep in mind the time integral of effort, $p$, and the time integral of flow, $q$. Often, the electrical domain is adopted for illustrating the BG concepts; thus, we have voltage $v$, current $i$, flux linkage $\lambda$ and charge $q$ as the analogous variables.

Four groups of symbols are used in BGs, namely two active elements, three one-port elements, two twoport elements and two junctions. The active ports are denoted by 'effort source' (SE) and 'flow source' (SF) represented in Table 2. In the electrical domain they are the voltage and current sources, respectively. In what concerns the one-port elements we have two energy stores and one energy dissipator, that is, $f=\varphi^{-1}(p)$, $e=\psi^{-1}(q)$ and $e=\gamma(f)$ (or, $f=\gamma^{-1}(e)$ ), respectively. In the electrical domain we have correspondingly the inductor $L$, capacitor $C$ and resistor $R$ with constitutive linear relations $i=\frac{1}{L} \lambda, v=\frac{1}{C} q$ and $v=R i$, respectively. Figure 2 shows the socalled tetrahedron of states, illustrating the relationships between the state variables.

Besides the three classical one-port elements, it was recognized to be possible a fourth element denoted memristor $M$ interconnecting $p$ and $q[16-18,30,64$, 75]. In fact, besides these elements it is possible to 
Table 1 Bond graph domains and variables

\begin{tabular}{|c|c|c|c|c|c|c|}
\hline Domain & Effort $e$ & Flow $f$ & Momentum $p$ & Displacement $q$ & Power $P$ & Energy $E$ \\
\hline \multirow[t]{2}{*}{ Electric } & Voltage & Current & Flux linkage & Charge & Power & Energy \\
\hline & $v$ & $i$ & $\lambda=\int v \mathrm{~d} t$ & $q=\int i \mathrm{~d} t$ & $P=e \cdot i$ & $E=\int P \mathrm{~d} t$ \\
\hline Units & {$[\mathrm{V}]$} & {$[\mathrm{A}]$} & {$[\mathrm{Vs}]$} & {$[\mathrm{C}]$} & {$[\mathrm{V} A=\mathrm{W}]$} & {$[\mathrm{V}$ As $=\mathrm{J}]$} \\
\hline \multirow[t]{4}{*}{ Magnetic } & Magnetomotive & Magnetic & Charge & Magnetic & Power & Energy \\
\hline & force & flux rate & linkage & flux & & \\
\hline & $e_{m}$ & $\dot{\phi}$ & $\Gamma=\int e_{m} \mathrm{~d} t$ & $\phi=\int \dot{\phi} \mathrm{d} t$ & $P=e_{m} \dot{\phi}$ & $E$ \\
\hline & {$[\mathrm{A}]$} & {$\left[\mathrm{Wbs}^{-1}\right]$} & {$[\mathrm{C}=\mathrm{As}]$} & {$[\mathrm{Wb}]$} & {$\left[\mathrm{A} \mathrm{Wbs} \mathrm{Wb}^{-1}=\mathrm{W}\right]$} & {$[\mathrm{A} \mathrm{Wb}=\mathrm{J}]$} \\
\hline \multirow{3}{*}{$\begin{array}{l}\text { Mechanics } \\
\quad \text { (translation) }\end{array}$} & Force & Velocity & Momentum & Displacement & Power & Energy \\
\hline & $f$ & $\dot{x}$ & $p=\int f \mathrm{~d} t$ & $x=\int \dot{x} \mathrm{~d} t$ & $P=f \cdot \dot{x}$ & $E$ \\
\hline & {$[\mathrm{N}]$} & {$\left[\mathrm{ms}^{-1}\right]$} & {$[\mathrm{Ns}]$} & {$[\mathrm{m}]$} & {$\left[\mathrm{Nms}^{-1}=\mathrm{W}\right]$} & {$[\mathrm{V}$ As $=\mathrm{J}]$} \\
\hline \multirow{4}{*}{$\begin{array}{r}\text { Mechanics } \\
\text { (rotation) }\end{array}$} & Torque & Angular & Angular & Angle & Power & Energy \\
\hline & & velocity & momentum & & & \\
\hline & $\tau$ & $\omega$ & $h=\int \tau \mathrm{d} t$ & $\theta=\int \omega \mathrm{d} t$ & $P=\tau \cdot \omega$ & $E$ \\
\hline & {$[\mathrm{Nm}]$} & {$\left[\mathrm{rad} \mathrm{s}^{-1}\right]$} & {$[\mathrm{N} \mathrm{ms}]$} & {$[\mathrm{rad}]$} & {$[\mathrm{W}]$} & {$[\mathrm{J}]$} \\
\hline \multirow[t]{4}{*}{ Hydraulic } & Pressure & Volume & Pressure & Volume & Power & Energy \\
\hline & & & momentum & flow rate & & \\
\hline & $p$ & $q$ & $\Gamma=\int p \mathrm{~d} t$ & $V=\int q \mathrm{~d} t$ & $P=p \cdot q$ & $E$ \\
\hline & {$\left[\mathrm{N} \mathrm{m}^{-2}\right]$} & {$\left[\mathrm{m}^{3} \mathrm{~s}^{-1}\right]$} & {$\left[\mathrm{Nsm}^{-2}\right]$} & {$\left[\mathrm{m}^{3}\right]$} & {$[\mathrm{W}]$} & {$[\mathrm{J}]$} \\
\hline \multirow[t]{4}{*}{ Chemical } & Chemical & Molar & - & Number & Power & Energy \\
\hline & potential & flow & & of moles & & \\
\hline & $\mu$ & $\dot{N}$ & & $N=\int \dot{N} \mathrm{~d} t$ & $P$ & $E$ \\
\hline & {$\left[\mathrm{J} \mathrm{mole}^{-1}\right]$} & {$\left[\mathrm{mole} \mathrm{s}^{-1}\right]$} & & [mole] & {$[\mathrm{W}]$} & {$[\mathrm{J}]$} \\
\hline \multirow[t]{3}{*}{ Thermo-dynamics } & Temperature & Entropy flow & - & Entropy & Power & Energy \\
\hline & $T$ & $\dot{S}$ & & $S=\int \dot{S} \mathrm{~d} t$ & $P$ & $E$ \\
\hline & {$[\mathrm{K}]$} & {$\left[\mathrm{JK}^{-1} \mathrm{~s}^{-1}\right]$} & & {$\left[\mathrm{JK}^{-1}\right]$} & {$[\mathrm{W}]$} & {$[\mathrm{J}]$} \\
\hline \multirow[t]{4}{*}{ Architecture } & Energy for a & Number of changes & Momentum & Displacement & Power & Energy \\
\hline & unit of change & in a unit of time & & & & \\
\hline & $e$ & $f$ & $p_{a}$ & $q$ & $P$ & $E$ \\
\hline & [energy/change] & [change/time] & [energy time/change] & [change] & [energy/time] & [energy] \\
\hline \multirow[t]{3}{*}{ Micro-economy } & Unit price of & Commodity & Economic & Accumulation & Money flow & Money \\
\hline & commodity & flow rate & impulse & of orders & & \\
\hline & $e$ & $f$ & $\lambda=\int e \mathrm{~d} t$ & $q=\int f \mathrm{~d} t$ & $\dot{M}=e f$ & $M=\int \dot{M} \mathrm{~d} t$ \\
\hline Units & {$\left[\$\right.$ unit $\left.^{-1}\right]$} & [unit period ${ }^{-1}$ ] & {$\left[\$\right.$ unit $^{-1}$ period $]$} & [unit] & {$\left[\$\right.$ period $\left.^{-1}\right]$} & \\
\hline \multirow[t]{4}{*}{ Macro-economy } & GDP per & Population & Economic & Population & Money flow & Money \\
\hline & capita & flow & impulse & & & \\
\hline & $Y$ & $\dot{n}$ & $I$ & $n$ & $\dot{M}=Y \dot{n}$ & $M=\int \dot{M} \mathrm{~d} t$ \\
\hline & {$\left[\$\right.$ capita $\left.^{-1}\right]$} & capita period $\left.^{-1}\right]$ & {$\left[\$\right.$ capita $^{-1}$ period $]$} & [capita] & {$\left[\$\right.$ period $\left.^{-1}\right]$} & {$[\$]$} \\
\hline
\end{tabular}

generalize the concepts, not only to higher order elements [31,72], but also to fractional order inductors and capacitors $[19,26,39,45,47]$, often called in the electrical domain as 'fractductors' and 'fractances', with constitutive relations $v=L \mathcal{D}_{t}^{\beta} i(t), 0<\beta<1$, and $i=C \mathcal{D}_{t}^{\alpha} v(t), 0<\alpha<1$, respectively [32,40], where symbol $\mathcal{D}_{t}^{\alpha}$ denotes the fractional derivative of order $\alpha$ with respect to time $t[34,46,49,55,57]$. 


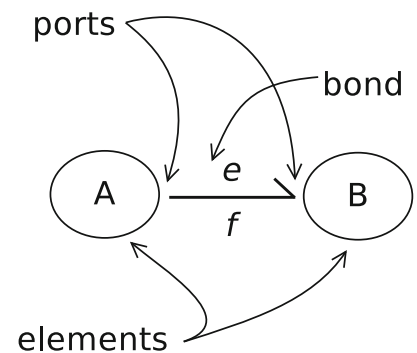

Fig. 1 Bond between elements $A$ and $B$

The BG elements are connected by means of twoport devices and junctions (see Table 2). The transformer $T F$ and gyrator $G Y$ are two-port elements that modify the input $\left\{e_{1}, f_{1}\right\}$ into the output $\left\{e_{2}, f_{2}\right\}$ (or the primary into the secondary) variables, being power conservative, that is, with $e_{1} f_{1}=e_{2}, f_{2}$. The constitutive relations are given by $\left\{e_{1}=m e_{2}, f_{2}=m f_{1}\right\}$ and $\left\{e_{1}=r f_{2}, e_{2}=r f_{1}\right\}$, where $m \in \mathbb{R}^{+}$and $r \in \mathbb{R}^{+}$are the transformer and gyrator modulus, respectively. On the other hand, the 1- (or effort) and 0- (or flow) junctions implement continuity constraints on the effort and flow variables, respectively. The constitutive relations correspond to $\left\{e_{1}+\cdots+e_{n}=0, f_{1}=\cdots=f_{n}\right\}$ for the 1 -junction and $\left\{e_{1}=\cdots=e_{n}, f_{1}+\cdots+f_{n}=0\right\}$ for the 0 -junction. In the electrical domain the 1 - and 0 junctions correspond to the first (or voltage) and second (or current) Kirchoff laws, respectively.

The notion of 'causality' is not usually discussed during system equation derivation. However, in BG causality is an important concept and allows the input/output roles of effort and flow to be included into the graph. This is represented using the causal stroke convention. In BG notation, a causal stroke added to one end of the bond indicates that the opposite side is establishing the effort. Symmetrically, the bond side with the causal stroke defines the flow. Assigning

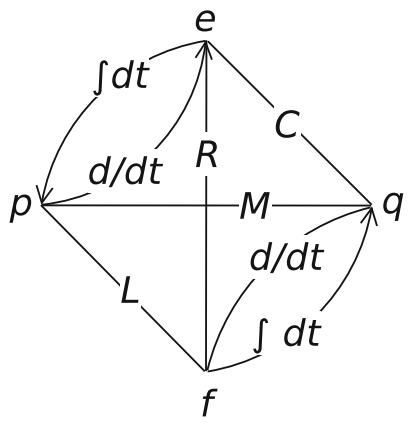

Fig. 2 Tetrahedron of states $\{e, f, p, q\}$
Table 2 Bond graph elements and ports: symbols, causality and relations

\begin{tabular}{|c|c|c|c|}
\hline Element & Symbol & Constitutive relations & Type \\
\hline Effort source & $S_{e} \stackrel{e}{y}$ & $e(t)$ given, $f(t)$ arbitrary & One-port \\
\hline Flow source & $S_{f} \longmapsto_{f}$ & $f(t)$ given, $e(t)$ arbitrary & One-port \\
\hline Effort store & $\frac{e}{f} \mid L$ & $f=\frac{1}{L} p$ & One-port \\
\hline Flow store & $\stackrel{e}{f}_{f} C$ & $e=\frac{1}{C} q$ & One-port \\
\hline Dissipator & $\begin{array}{l}\stackrel{e}{f}_{f}^{e} R \\
\frac{e}{f}\end{array} R$ & $\begin{array}{l}e=R f \\
f=\frac{1}{R} e\end{array}$ & One-port \\
\hline Transformer & 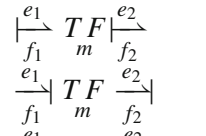 & $\begin{array}{l}e_{1}=m e_{2} \\
f_{2}=m f_{1}\end{array}$ & Two-port \\
\hline Gyrator &  & $\begin{array}{l}e_{1}=r f_{2} \\
e_{2}=r f_{1}\end{array}$ & Two-port \\
\hline Effort or 1-junction &  & $\begin{array}{l}e_{1}+e_{2}+\cdots+e_{n}=0 \\
f_{1}=f_{2}=\cdots=f_{n}\end{array}$ & Junction \\
\hline Flow or 0 -junction & $\frac{e_{1}}{f_{2}} \bar{f}_{f_{1}} Y_{e_{2}} \cdot \stackrel{\cdot \cdot}{f_{n}}$ & $\begin{array}{l}e_{1}=e_{2}=\cdots=e_{n} \\
f_{1}+f_{2}+\cdots+f_{n}=0\end{array}$ & Junction \\
\hline
\end{tabular}


Table 3 Effort store, flow store and dissipator elements

\begin{tabular}{cllllll}
\hline Domain & $\begin{array}{l}\text { Element } \\
\text { type }\end{array}$ & Name & $\begin{array}{l}\text { Symbol } \\
\text { relation }\end{array}$ & $\begin{array}{l}\text { Dynamic } \\
\text { relation }\end{array}$ & $\begin{array}{l}\text { Linear } \\
\text { relation }\end{array}$ & Units \\
\hline Electric & Effort store & Inductor & $L$ & $i=\varphi^{-1}(\lambda)$ & $i=\frac{1}{L} \lambda$ & {$\left[\mathrm{H}^{2} \mathrm{~m}^{2} \mathrm{~kg} \mathrm{~s}^{-2} \mathrm{~A}^{-2}\right]$} \\
& Flow store & Capacitor & $C$ & $v=\psi^{-1}(q)$ & $v=\frac{1}{C} q$ & {$\left[\mathrm{~F}=\mathrm{s}^{4} \mathrm{~A}^{2} \mathrm{~m}^{-2} \mathrm{~kg}^{-1}\right]$} \\
& Dissipator & Resistor & $R$ & $v=\gamma(i)$ & $v=R i$ & {$\left[\Omega=\mathrm{kg} \mathrm{m}^{2} \mathrm{~s}^{-3} \mathrm{~A}^{-2}\right]$} \\
Micro & Effort store & Inertia & $I_{e}$ & $f=\varphi^{-1}(\lambda)$ & $f=\frac{1}{I_{e}} \lambda$ & {$\left[\$ \mathrm{unit}^{-2} \mathrm{period}^{2}\right]$} \\
economy & Flow store & Compliance & $C_{e}$ & $e=\psi^{-1}(q)$ & $e=\frac{1}{C_{e}} q$ & {$\left[\$ \mathrm{unit}^{2}\right]$} \\
& Dissipator & Resistor & $R_{e}$ & $e=\gamma(f)$ & $e=R_{e} f$ & {$\left[\$ \mathrm{unit}^{-2} \mathrm{period}\right]^{-1}$} \\
Macro & Effort store & Inertia & $I_{e}$ & $\dot{n}=\varphi^{-1}(I)$ & $\dot{n}=\frac{1}{L_{e} I}$ & {$\left[\$ \mathrm{capita}^{-2} \mathrm{period}^{2}\right]$} \\
economy & Flow store & Compliance & $C_{e}$ & $Y=\psi(n)$ & $Y=\frac{1}{C_{e}} n$ & {$\left[\$ \mathrm{capita}^{2}\right]$} \\
& Dissipator & Resistor & $R_{e}$ & $Y=\gamma(\dot{n})$ & $Y=R_{e} \dot{n}$ & {$\left[\$ \mathrm{capita}^{-2} \mathrm{period}\right]^{-1}$} \\
\hline
\end{tabular}

causality in a BG allows the detection of degeneracies in the system modelling. This problem occurs in situations where one or more algebraic loops exist, and the one or more state variables are linearly dependent on the rest. Causality strokes are represented in Table 2.

\section{Bond graph modelling of economic systems}

In 1975 Brewer [9] extended the BG concepts to microeconomy. Later the work was continued in [10-12]. Brewer considered effort and flow state variables to be the 'unit price of commodity' and 'commodity flow rate', respectively. Power and energy have for analogous variables 'money flow' and 'money', representing a generalization of the standard physical variables. The related dynamical concepts are shown in Tables 1 and 3.

In what concerns the effort and flow junctions Brewer mentions that a 'proper cash accounting', known as Walras' law to economists, leads to the requirement $e_{1} f_{1}+\cdots+e_{n} f_{n}=0$. This principle is not totally clear in macro-economy, although, at least for a given time instant, a healthy environment would lead us to such supposition. This 'power-conservative principle' comes from considering that different sectors of any economy are related to each other and lead to consider a system of $n$ equations describing those relationships, using $n$ variables. To reach a general equilibrium, a successive iteration of price adjustments is required, in order that all excess demand over supply would become zero [73]. Such a 'power-conservative principle' had also been established much earlier among economists, such as Adam Smith, James Mill and Jean Baptiste Say, who considered that the production of final goods gives origin to a distribution of revenues to pay for the use of input factors during the productive process, and such revenues are available to buy those final goods, at last [58]. Say's law currently, is coined as saying 'Supply generates Demand'. It is only not clear for macro-economic equilibrium in monetized societies, if hoarding will occur because sub-consumption means crisis (as scarce consumption for production is equivalent to an over-production situation). However, in a dynamic perspective crises can be overcome and a new general equilibrium may be reached. In the sequel we overcome using junctions by considering a generalized one-port element.

In this work we intend to extend the concepts introduced by Brewer to macro-economy. In our formulation the effort and flow variables are represented by the 'GDP per capita', $Y(t)$ and 'Population flow' $\dot{n}(t)$. Therefore, power and energy are similar to Brewer proposal, namely 'money flow' $\dot{M}(t)$ and 'money' $M(t)$. The associated dynamic variables and elements are shown in Tables 1 and 3.

Figure 3 shows, for example, the state space portrait $\{Y, \dot{n}\}$ of BRA, CHN, DEU and USA during 19602010.

We observe a complex dynamical relationship between the two variables that poses problems for an accurate modelling. Brewer discussed analytically some possible non-linear relations between effort and flow in micro-economy, but in our case we follow a distinct approach for macro-economy. First we make use of real data, and we shall verify how the BG model fits in. 

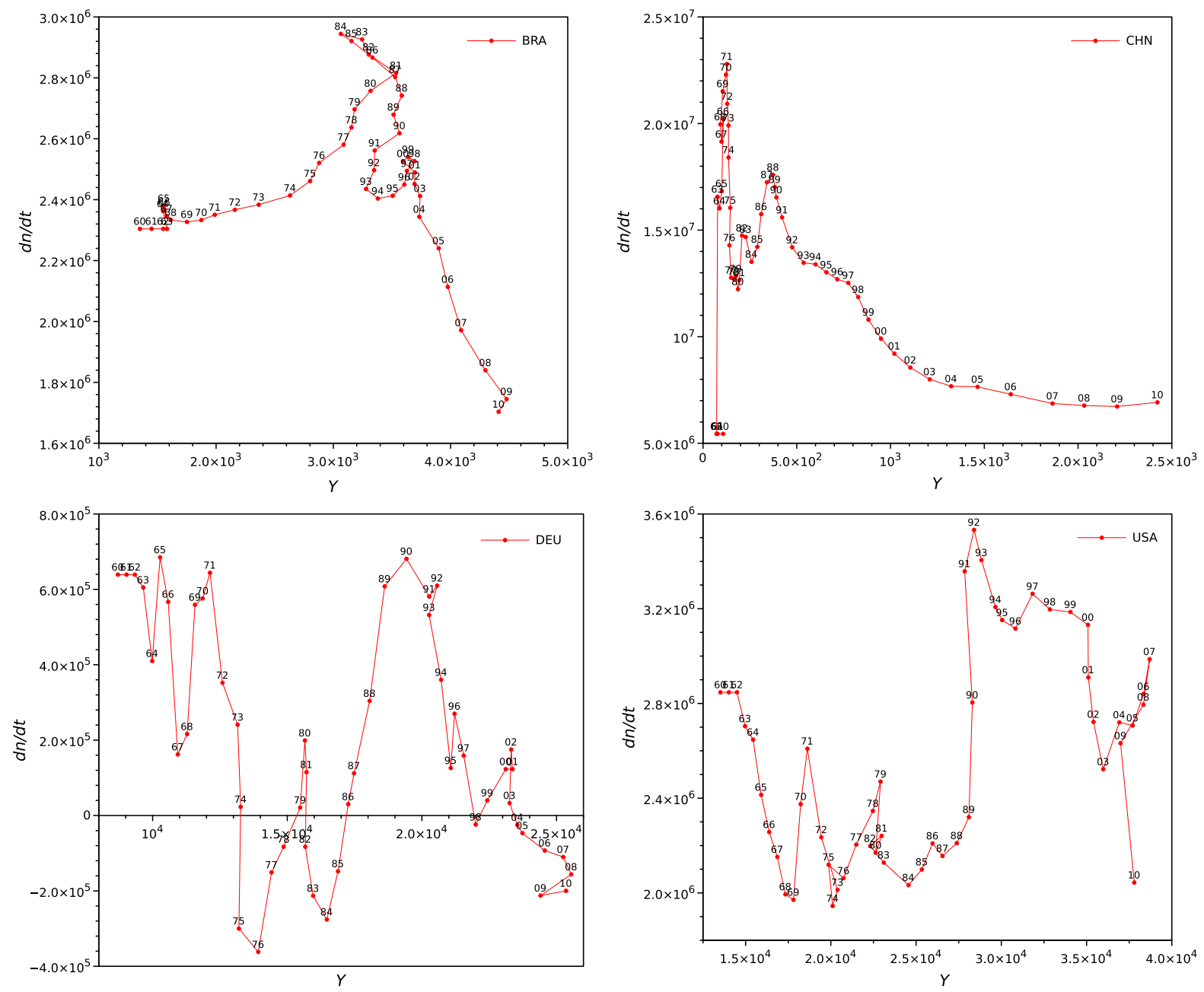

Fig. 3 State space portrait $\{Y, \dot{n}\}$ of BRA, CHN, DEU and USA during 1960-2010

Second, we consider a linear relation between effort and flow by means of a generalized fractional-order element:

$\dot{n}(t)=C \mathcal{D}_{t}^{\alpha} Y(t), \quad C, \alpha \in \Re$,

Third, we allow parameters $\{C, \alpha\}$ to be variable in time and to have both positive and negative values, so that they can adapt to the changing conditions in data.

Several issues need to be clarified before continuing. We note that the generalized one-port element (1) allows us to avoid using the interconnection of several integer order one-port elements while using only two parameters. We observe also that negative/positive values of $C$ mean an active/passive element, while posi- tive/negative values of $\alpha$ represent capacitive/inductive elements (in the electrical domain). It should be highlighted that in classical terms we have $|\alpha| \leq 1$, but as pointed by [31,72], values outside this range are possible. For example, the frequency-dependent negative resistor (FDNR) $[14,59,62]$ implements easily the second-order constitutive equation $i=D \mathcal{D}_{t}^{2} v$, where $D$ is a parameter, used in electronic filters.

The database for 50 countries includes GDP and population for a five decades time span, sampled with one year period (Table 4). Data were collected from the World Bank national development indicators to cover the period coming from 1960 to 2010 :

(1) GDP per capita comes from NY.GNP.PCAP.KD. It is the GNI per capita (constant 2,000 US\$). GNI per 
capita is gross national income divided by midyear population. GNI (formerly GNP) is the sum of value added by all resident producers plus any product taxes (less subsidies) not included in the valuation of output plus net receipts of primary income (compensation of employees and property income) from abroad. Data are in constant 2,000 U.S. dollars (http://data.worldbank.org/indicator/NY.GNP. PCAP.KD).

(2) Population density comes from EN.POP.DNST. It is the people per sq. $\mathrm{km}$ of land area. Population density is midyear population divided by land area in square kilometres. Population is based on the de facto definition of population, which counts all residents regardless of legal status or citizenshipexcept for refugees not permanently settled in the country of asylum, who are generally considered part of the population of their country of origin. Land area is a country's total area, excluding area under inland water bodies, national claims to continental shelf, and exclusive economic zones. In most cases the definition of inland water bodies includes major rivers and lakes (http://data.worldbank.org/ indicator/EN.POP.DNST).

For implementing the fractional-order relation (1) it is adopted the Grünwald-Letnikov formulation of definition of fractional derivative:

${ }_{a}^{G L} \mathcal{D}_{t}^{\alpha} f(t)=\lim _{h \rightarrow 0} \frac{1}{h^{\alpha}} \sum_{j=0}^{\left[\frac{t-a}{h}\right]}(-1)^{j}\left(\begin{array}{c}\alpha \\ j\end{array}\right) f(t-j h), \quad t>a$,

where $\Gamma(\cdot)$ is Euler's gamma function, $[x]$ means the integer part of $x$, and $h$ is the step time increment.

In the numerical algorithm for calculating $\mathcal{D}_{t}^{\alpha}$ the time increment $h$ is approximated by the sampling period $T_{S}$, and the series is truncated at the $r$-th term yielding:

$\mathcal{D}^{\alpha}[f(t)] \approx \frac{1}{T_{s}^{\alpha}} \sum_{k=0}^{r}(-1)^{j} \frac{\Gamma(\alpha+1)}{j ! \Gamma(\alpha-j+1)} f\left(t-j T_{s}\right)$.

Other techniques adopt the Laplace or the $Z$ transforms and lead to rational fractions $[15,38,41,56]$. In our case, since time series have one single sample per year, it is adopted the series truncation method with $T_{s}=1$.
For estimating the values of the parameters $\{C, \alpha\}$ it was used a genetic algorithm (GA) due to its simplicity and robustness. In brief, the GAs are a computational technique to find exact or approximate solutions in optimization problems [25,28,37]. A GA consists in a population representing candidate solutions of an optimization problem that evolves (computationally) towards better solutions. The GA starts by initializing the population of solutions randomly, and improves them by means of the repetitive application of mutation, crossover and selection operators. In each iteration the fitness of every individual in the population is evaluated, and the best individuals are selected to form part of the new population. The GA terminates when either the maximum number of generations is produced, or a satisfactory fitness level has been reached.

We adopt a GA population of 400 elements, 400 iterations and a fitness function $J$ given by

$$
\begin{aligned}
& \dot{n}_{a}(k)=C \sum_{j=0}^{r}(-1)^{j} \frac{\Gamma(\alpha+1)}{j ! \Gamma(\alpha-j+1)} Y(k-j) \\
& J=\sum_{k=0}^{r}\left\{\dot{n}(k)-\dot{n}_{a}(k)\right\}^{2},
\end{aligned}
$$

where $k$ is the discrete time index, $\dot{n}_{a}$ denotes the approximation to the flux $\dot{n}$ based on the effort $Y$. The upper limit $r$ represents the total number of points involved in the fitting procedure and the memory length in (3). We decided to adopt a sliding window of one point for each calculation. This means that there is an overlap of $r-1$ years between 2 consecutive time windows.

Several experiments demonstrated that the fitting between $\dot{n}$ and $\dot{n}_{a}$ was very good (see Fig. 4 ) at the cost of a strong variability of the parameters. For example, Fig. 5 shows the variation of $\{C, \alpha\}$ versus time for USA, with $r=12$, during 1960-2010. It was observed that the effect of $r$ upon this variability was minor. Figure 6 depicts the contour plots of $\{C, \alpha\}$ versus $r$ and time for USA, where is visible the propagation of the economical variations horizontally, apparently with a minor influence of $r$.

Plotting the variation of the parameters in the locus $\{C, \alpha\}$ leads to the emergence of a distinct pattern for each country. For example, Fig. 7 shows the patterns of BRA, CHN, DEU and USA in the locus $\{C, \alpha\}$, with $r=12$, during 1960-2010.

In order to capture the signature of each country and to describe the world dynamics it was decided 
Table 4 Countries and labels

\begin{tabular}{|c|c|c|c|c|c|}
\hline No. & Label & Country & No. & Label & Country \\
\hline 1 & ARG & Argentina & 26 & IRL & Ireland \\
\hline 2 & AUS & Australia & 27 & IRN & Iran \\
\hline 3 & AUT & Austria & 28 & ITA & Italy \\
\hline 4 & BEL & Belgium & 29 & JPN & Japan \\
\hline 5 & BRA & Brazil & 30 & KOR & Korea \\
\hline 6 & $\mathrm{CAN}$ & Canada & 31 & LUX & Luxembourg \\
\hline 7 & $\mathrm{CHE}$ & Switzerland & 32 & MEX & Mexico \\
\hline 8 & CHL & Chile & 33 & MYS & Malaysia \\
\hline 9 & $\mathrm{CHN}$ & China & 34 & NGA & Nigeria \\
\hline 10 & COG & Congo & 35 & NLD & Netherlands \\
\hline 11 & $\mathrm{COL}$ & Colombia & 36 & NOR & Norway \\
\hline 12 & DEU & Germany & 37 & NZL & New Zealand \\
\hline 13 & DNK & Denmark & 38 & PAK & Pakistan \\
\hline 14 & DZA & Algeria & 39 & PHL & Philippines \\
\hline 15 & EGY & Egypt & 40 & PRT & Portugal \\
\hline 16 & ESP & Spain & 41 & SAU & Saudi Arabia \\
\hline 17 & FIN & Finland & 42 & SGP & Singapore \\
\hline 18 & FRA & France & 43 & SWE & Sweden \\
\hline 19 & GBR & United Kingdom & 44 & THA & Thailand \\
\hline 20 & GRC & Greece & 45 & TUR & Turkey \\
\hline 21 & HUN & Hungary & 46 & URY & Uruguay \\
\hline 22 & ICE & Iceland & 47 & USA & United States \\
\hline 23 & IDN & Indonesia & 48 & VEN & Venezuela \\
\hline 24 & IND & India & 49 & ZAF & South Africa \\
\hline 25 & ISR & Israel & 50 & ZWE & Zimbabwe \\
\hline
\end{tabular}

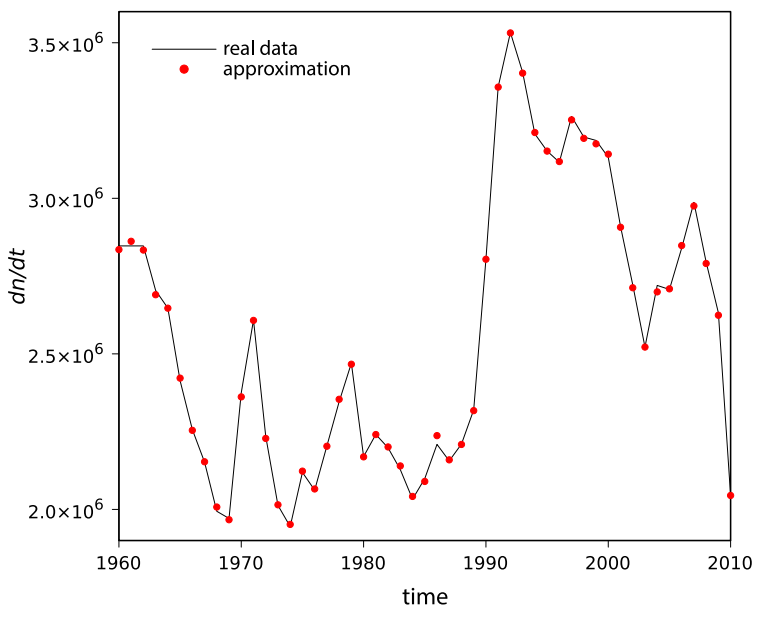

Fig. 4 Variation of $\dot{n}(t)$ and $\dot{n}_{a}(t)$, with $r=12$, versus time for USA during 1960-2010

to calculate the median of the parameters $\{C, \alpha\}$. The median is more robust than the arithmetic average since it has a smaller sensitivity to outliers. Figure 8 shows the 50 countries represented in the locus $\{C, \alpha\}$. Given the high concentration of points (countries) near the origin in Fig. 9 is represented a magnification of that area. The surface of each circle is proportional to the variability of $\alpha$, namely to the interquartile range of its variation along the period 1960-2010.

In fact, the locus $\{C, \alpha\}$ was drawn for $r=2$ up to $r=15$. For example, Figs. 10 and 11 depict the locus $\{C, \alpha\}$ for $r=9$ and $r=15$, respectively. It was observed that changing between two consecutive values of $r$ had the effect of rotating the chart, while maintaining the general layout approximately. Therefore, points were moved from the 4th up to the 1st quadrant, being the limit value $r=12$. Larger values of $r$ had minor effect upon the chart, and it was concluded that 12 years were the adequate value for $r$ to capture adequately the memory of the phenomenon.

We verify the emergence of a pattern, and we start by a simple analytical discussion. The elements are of the 'capacitive type' $(\alpha>0)$ as one should expect 

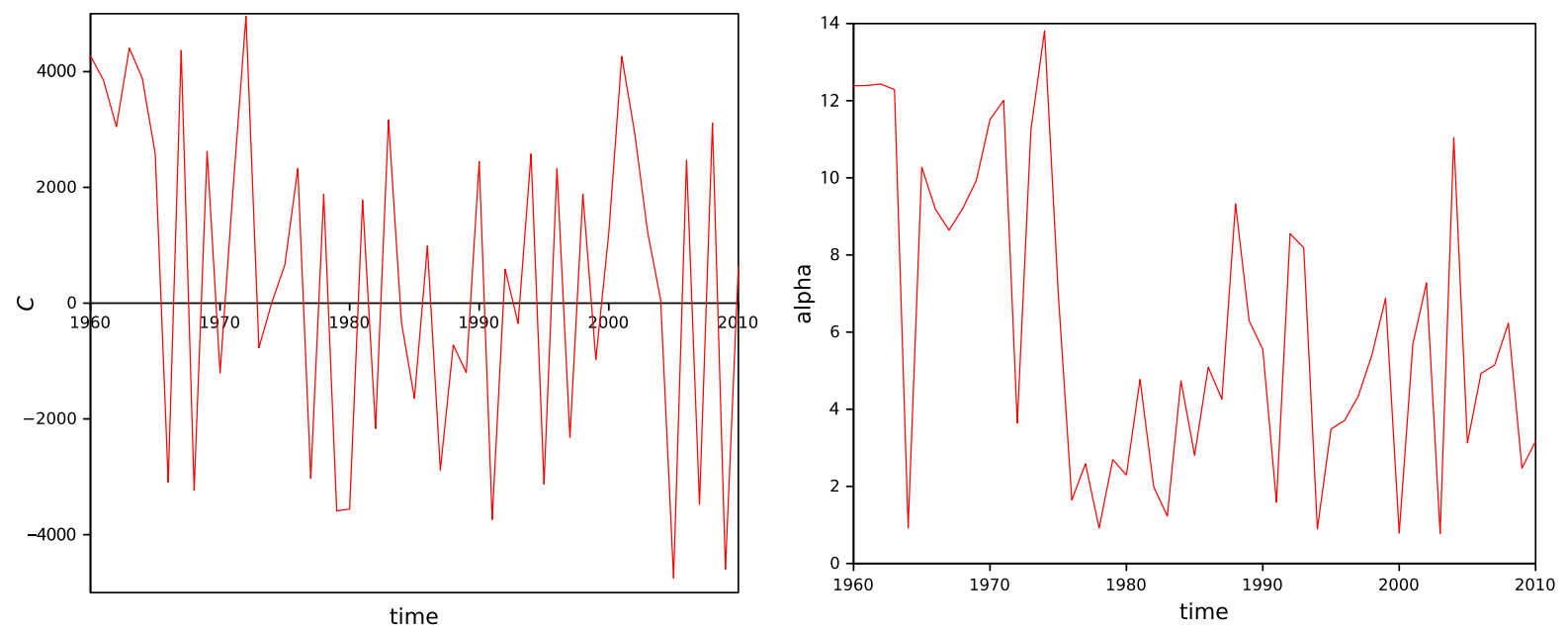

Fig. 5 Variation of the parameters $\{C, \alpha\}$, with $r=12$ versus time for USA during 1960-2010
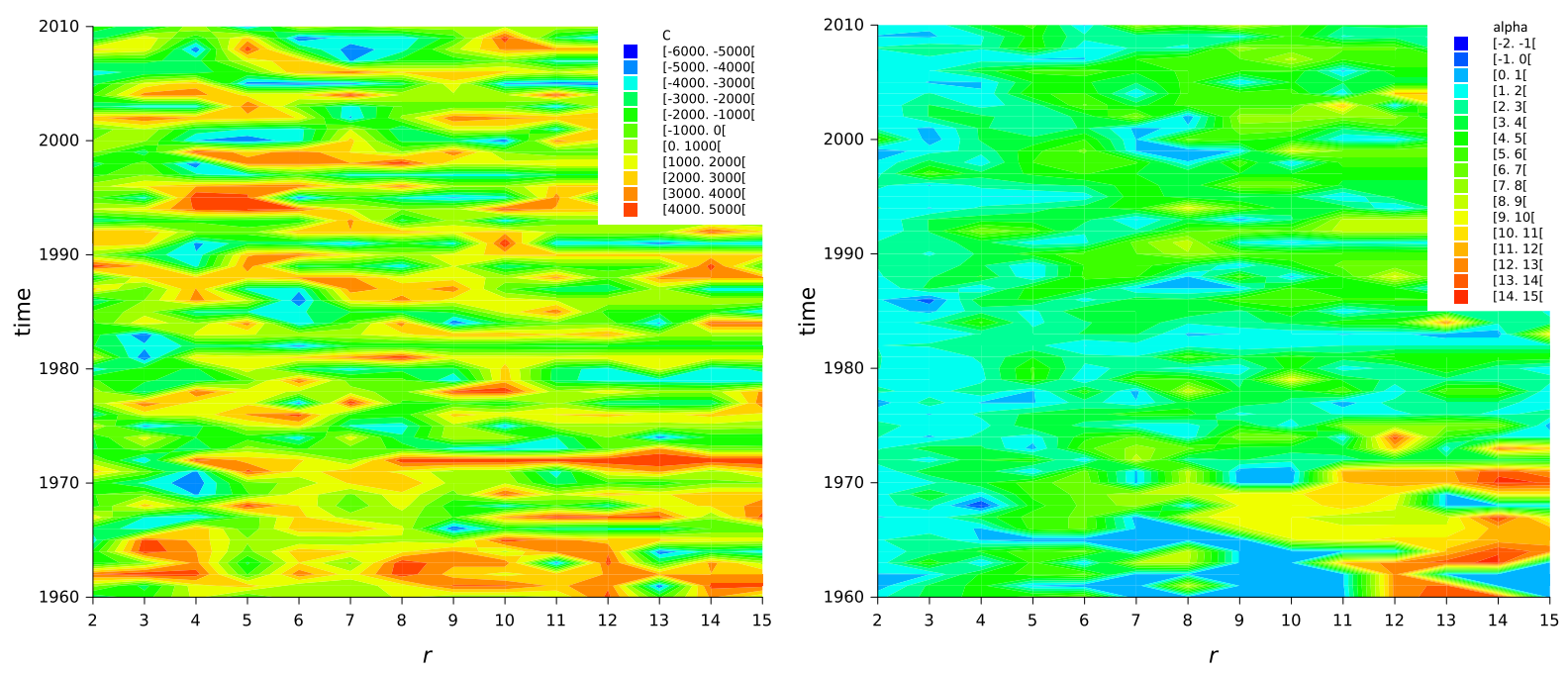

Fig. 6 Contour plots of $\{C, \alpha\}$ versus $r$ and time for USA during 1960-2010

since effort $Y(t)$ has a smooth variation, while the flux $\dot{n}(t)$ reveals a very volatile behaviour. A central part, constituted manly by the European countries, JPN and USA, remained invariant, but the new economies, such as BRA, CHN and IND, rotated anticlockwise while increasing $r$. As mentioned previously the effect stabilized for $r=12$. A more detailed analysis of the results from an economical point of view is developed in the next section.

\section{Discussion}

State space portraits are very different, as the four extreme cases depicted in Fig. 3 can show. Figure 8 is an accurate view of the last half-century economic trends in a global perspective. Its main message says that scale matters: the human creative powers matter as well as the departing GDP per capita levels. Economic development follows the traced eigen-vector. The world economic system is very sensitive to the selected vital variables representing scale, indeed.

The developed countries form a large node of highstandard patterns of life and welfare in the locus $\{C, \alpha\}$, with $r=12$. They were the large-scale economies at the departing moment. Independently from their territory dimension they were the large-scale national economies in the global scene. Several other countries are following this pattern. The promising new 


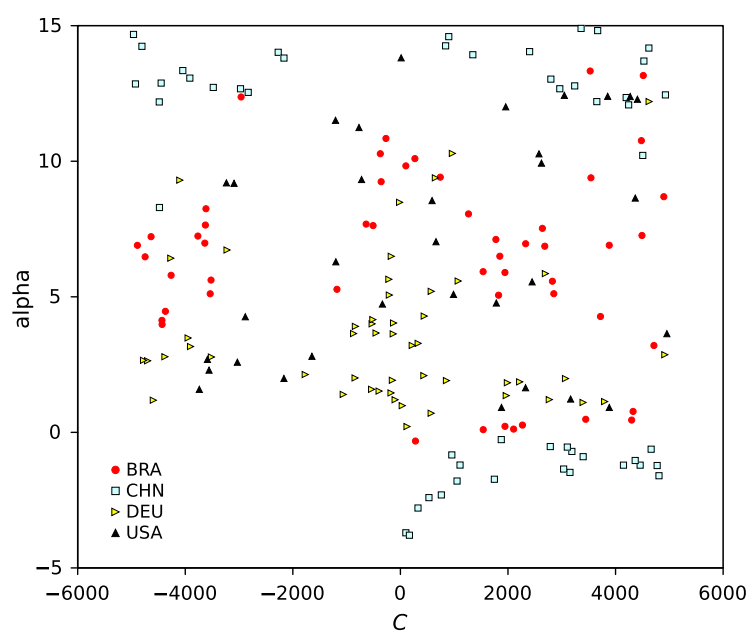

Fig. 7 Patterns of BRA, CHN, DEU and USA in the locus $\{C, \alpha\}$, with $r=12$, during 1960-2010

performers include the large far-Asian partners (China, India, Indonesia, Thailand, Pakistan and Philippines), and the large South-American Brazil. Independently from their lateness in industrializing and modernizing they are huge at the departing moment, and this fact commands their performance in globalization.
The European-neighbouring countries (Iran, Egypt, Turkey) and South-Central-American partners (such as Argentina, Colombia and Mexico) present large potential similarities for growth among them and with the Western partners, too. However, similarities among the partners belonging to the Western wealthy world are so much stronger that they all overlap. A magnified representation of the central part of the locus is required (Fig. 9). The node includes the European continent, Japan, Canada and the USA. Germany is a bit dissimilar from the other European states and is commanding them.

A remarkable feature in the universe of the countries belonging to this node has been the flourishing of democracy, while rapid economic growth provided superior competitive advantages, higher wages and mobility $[13,35]$.

It is out of the scope of this paper to discuss if economic growth spread will bring a global democracy system or will move to the future Asian great power political regimes, as the Nobel Prize Robert Fogel suggests [22].

As the high departing levels do matter in spite of the individual space portrait differences demonstrated in Fig. 3, territory scale matters in a historical perspective,
Fig. 8 Representation of the 50 countries in the locus $\{C, \alpha\}$, with $r=12$, for the period 1960-2010




Fig. 9 Magnified representation of the central part of the locus $\{C, \alpha\}$, with $r=12$, for the 50 countries and the period 1960-2010

Fig. 10 Representation of the 50 countries in the locus $\{C, \alpha\}$, with $r=9$, for the period 1960-2010
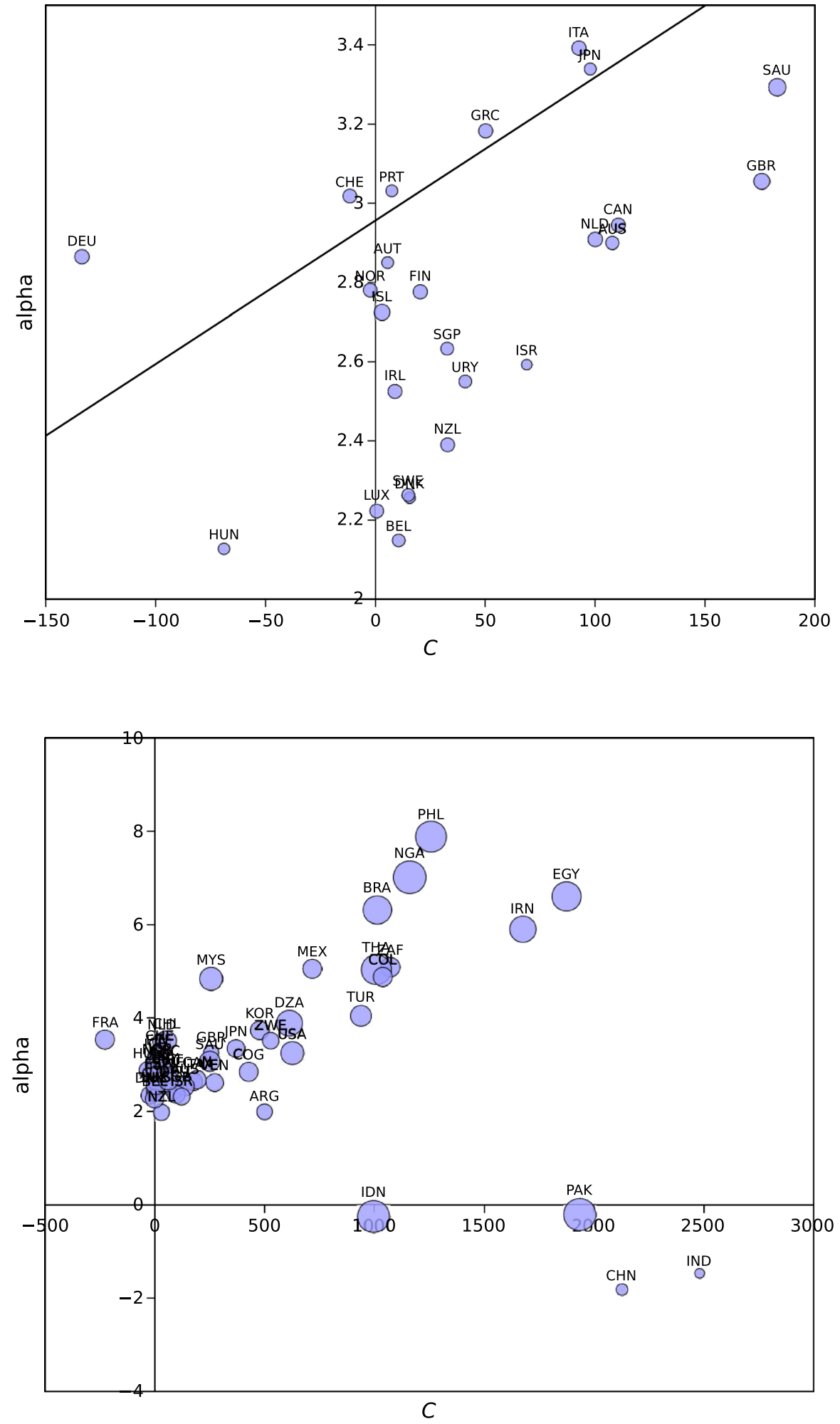
Fig. 11 Representation of the 50 countries in the locus $\{C, \alpha\}$, with $r=15$, for the period 1960-2010



because it has dictated the departing levels of performance. So, the small European countries' control over large territories in the past may deserve credibility, a hypothesis to be checked from the BG perspective [2].

\section{Conclusions}

Formal modelling in economics has the special aim of fitting theories to understand a complex world, because models reflect ideas that may be "more powerful than is commonly understood' [63].

The developed approach helps the perception of how our complex world has moved as a system. It also helps to frame a precise vision on how the future world may be like. Using simple assumptions, models may provide decisive insights into economic phenomena, and be part of the analysis for theoretical paradigms, putting in motion crucial ways for the humankind survival [5].

Models recall that day-to-day adjustments are not enough to view the whole economic picture, because constant small changes make up long-run trends for the whole pattern of changes in the global world [27]. To overlap the global economic system one may remember Shakespeare in saying that 'All the world's a stage, and all the men and women merely players' [61].
In this perspective, the paper presented a BG approach to the modelling of economies. Concepts proposed for micro-economy were generalized having in mind the macro-economy problem. In this context complex aspects such as the generalization of the principle of conservation of power and the assignment of causalities were circumvented by means of a variable fractional-order element. Several experiments analysed the influence of the memory effects and characterized the dynamical behaviour in the light of the fractional approach.

\section{References}

1. Acemoglu, D., Johnson, S., Robinson, J.A.: The colonial origins of comparative development: an empirical investigation. Am. Econ. Rev. 91(5), 1369-1401 (2001)

2. Acemoglu, D., Robinson, J.: Why Nations Fail: The Origins of Power, Prosperity, and Poverty. Profile Books, New York (2012)

3. Allen, R.C.: International competition in iron and steel, 1850-1913. J. Econ. Hist. 39(4), 911-937 (1979)

4. Allen, R.C.: American exceptionalism as a problem in global history. Oxford Discussion Paper Series, Number 689. University of Oxford, Department of Economics (2013). http://www.economics.ox.ac.uk/materials/ papers/13161/paper689.pdf 
5. Bacharach, M., Dempster, A., Enos, J. (eds.): Mathematical Models in Economics. Oxford University Press, Oxford (1994)

6. Baleanu, D., Diethelm, K., Scalas, E., Trujillo, J.J.: Fractional Calculus: Models and Numerical Methods. Series on Complexity, Nonlinearity and Chaos. World Scientific Publishing Company, Singapore (2012)

7. Borutzky, W.: Bond Graph Methodology: Development and Analysis of Multidisciplinary Dynamic System Models. Springer, London (2010)

8. Breedveld, P.C.: Thermodynamic bond graphs and the problem of thermal lnertance. J. Frank1. Inst. 314(1), 15-40 (1982)

9. Brewer, J.W.: Bond graphs of microeconomic systems. In: 75-WA/Aut-8. American Society of Mechanical Engineering, Houston (1975)

10. Brewer, J.W.: Structure and cause and effect relations in social systems simulations. IEEE Trans. Syst. Man Cybern. 7(6), 468-474 (1977)

11. Brewer, J.W.: Progress in the bond graph representations of economics and population dynamics. J. Frankl. Inst. 328(5/6), 675-696 (1991)

12. Brewer, J.W., Craig, P.P.: Bilinear, dynamic single-ports and bond graphs of economic systems. J. Frankl. Inst. 313(4), 185-196 (1982)

13. Broadberry, S.: The Productivity Race: British Manufacturing in International Perspective. Cambridge University Press, Cambridge (1997)

14. Bruton, L.T.: Network transfer functions using the concept of frequency dependent negative resistance. IEEE Trans. Circuit Theory 16, 406-408 (1969)

15. Chen, Y., Moore, K.: Discretization schemes for fractionalorder differentiators and integrators. IEEE Trans. Circuits Syst. I Fundam. Theory Appl. 49(3), 363-367 (2002)

16. Chua, L.O.: Memristor-the missing circuit element. IEEE Trans. Circuit Theory 18(2), 507-519 (1971)

17. Chua, L.O.: Nonlinear circuit foundations for nanodevices, Part I: the four-element torus. Proc. IEEE 91(11), 1830-1859 (2003)

18. Chua, L.O., Kang, S.M.: Memristive devices and systems. Proc. IEEE 64(2), 209-223 (1976)

19. Connolly, T.J., Contréras, J.A.: Bond graph primitives for modeling systems with fractional differential equations. Fract. Calc. Appl. Anal. 12(4), 391-408 (2009)

20. Crafts, N.: Steam as a general purpose technology: a growth accounting perspective. Econ. J. 114(495), 338-351 (2004)

21. Deskur, J.: Models of magnetic circuits and their equivalent electrical diagrams. Int. J. Comput. Math. Electr. Electron. Eng. 18(4), 600-610 (1999)

22. Fogel, R.W.: Capitalism and democracy in 2040 - forecasts and speculations. NBER Working Paper Series. The National Bureau of Economic Research, Cambridge (2007). http://www.nber.org/papers/w13184

23. Gawthrop, P.J., Bevan, G.P.: Bond-graph modeling: a tutorial introduction for control engineers. IEEE Control Syst. Mag. 27(2), 24-45 (2007)

24. Gawthrop, P.J., Smith, L.S.: Metamodelling: Bond Graphs and Dynamic Systems. Prentice Hall, Englewood Cliffs (1996)
25. Goldberg, D.E.: Genetic Algorithms in Search Optimization, and Machine Learning. Addison-Wesley, Reading (1989)

26. Guijarro, N., Dauphin-Tanguy, G.: Approximation methods to embed the non-integer order models in bond graphs. Sig. Process. 83(11), 2335-2344 (2003)

27. Hayek, F.: The use of knowledge in society. Am. Econ. Rev. 35(4), 519-530 (1945)

28. Holland, J.H.: Adaptation in Natural and Artificial Systems. The University of Michigan Press, Ann Arbor (1975)

29. Ionescu, C.: The Human Respiratory System: An Analysis of the Interplay between Anatomy, Structure, Breathing and Fractal Dynamics. Series in BioEngineerin. Springer, London (2013)

30. Jeltsema, D., Dòria-Cerezo, A.: Memristive portHamiltonian systems. Math. Comput. Model. Dyn. Syst. 16(2), 75-93 (2010)

31. Jeltsema, D., Dòria-Cerezo, A.: Port-Hamiltonian formulation of systems with memory. Proc. IEEE 100(6), 1928-1937 (2012)

32. Jesus, I.S., Machado, J.A.T.: Development of fractional order capacitors based on electrolyte processes. Nonlinear Dyn. 56(1-2), 45-55 (2009)

33. Karnopp, D., Rosenberg, R.C.: System Dynamics: A Unified Approach. Wiley, New York (1975)

34. Kilbas, A., Srivastava, H., Trujillo, J.: Theory and Applications of Fractional Differential Equations, vol. 204. NorthHolland Mathematics Studies, Elsevier (2006)

35. Long, J., Ferrie, J.: Intergenerational occupational mobility in Britain and the United States since 1850. Am. Econ. Rev. 103(4), 1109-1137 (2013)

36. Ma, C., Hori, Y.: Application of bond graph models to the representation of buildings and their use. In: Proceedings of American Control Conference, Boston, pp. 2901-2906 (2004)

37. Machado, J.A.T.: Calculation of fractional derivatives of noisy data with genetic algorithms. Nonlinear Dyn. 57(1-2), 253-260 (2009)

38. Machado, J.A.T.: Fractional derivatives: probability interpretation and frequency response of rational approximations. Commun. Nonlinear Sci. Numer. Simul. 14(9-10), 3492-3497 (2009)

39. Machado, J.A.T.: Fractional generalization of memristor and higher order elements. Commun. Nonlinear Sci. Numer. Simul. 18(12), 264-275 (2013)

40. Machado, J.A.T., Galhano, A.M.: Fractional order inductive phenomena based on the skin effect. Nonlinear Dyn. 68(12), 107-115 (2012)

41. Machado, J.T.: Analysis and design of fractional-order digital control systems. Syst. Anal. Model. Simul. 27(2-3), 107-122 (1997)

42. Machado, J.T., Galhano, A.M., Trujillo, J.J.: On development of fractional calculus during the last fifty years. Scientometrics 98, 577-582 (2013)

43. Machado, J.T., Kiryakova, V., Mainardi, F.: Recent history of fractional calculus. Commun. Nonlinear Sci. Numer. Simul. 16(3), 1140-1153 (2011)

44. Mainardi, F.: Fractional Calculus and Waves in Linear Viscoelasticity: An Introduction to Mathematical Models. Imperial College Press, London (2010) 
45. Méhauté, A.L., Nigmatullin, R.R., Nivanen, L.: Flèches du temps et géométrie fractale. Hermès, Paris (1998)

46. Miller, K., Ross, B.: An Introduction to the Fractional Calculus and Fractional Differential Equations. Wiley, New York (1993)

47. Moreau, X., Khemane, F., Malti, R., Serrier, P.: Approximation of a fractance by a network of four identical RC cells arranged in gamma and a purely capacitive cell. In: Baleanu, D., Machado, J.A.T., Güvenç, Z.B. (eds.) New Trends in Nanotechnology and Fractional Calculus Applications, pp. 107-120. Springer, Dordrecht (2001)

48. Mukherjee, A., Karmakar, R., Samantaray, A.K.: Bond Graph in Modeling, Simulation and Fault Identification. CRC Press, New Delhi (2006)

49. Oldham, K., Spanier, J.: The Fractional Calculus: Theory and Application of Differentiation and Integration to Arbitrary Order. Academic Press, New York (1974)

50. O'Rourke, K.: Tariffs and growth in the late 19th century. Econ. J. 110(463), 456-483 (2000)

51. O'Rourke, K., Williamson, J.G.: Globalization and History: The Evolution of a Nineteenth-Century Atlantic Economy. MIT Press, Cambridge (2001)

52. Oustaloup, A.: Systèmes asservis linéaires d'ordre fractionnaire: théorie et pratique. Masson, Paris (1983)

53. Paynter, H.: An Epistemic Prehistory of Bond Graphs. North-Holland, Amsterdam (1992)

54. Pease, D.E.: The New American Exceptionalism. Critical American Studies. University of Minnesota Press, Minneapolis (2009)

55. Podlubny, I.: Fractional differential equations. An Introduction to Fractional Derivatives, Fractional Differential Equations, to Methods of Their Solution, Mathematics in Science and Engineering, vol. 198. Academic Press, San Diego (1998)

56. Podlubny, I.: Fractional-order systems and $\mathrm{PI}^{\lambda} \mathrm{D}^{\mu}$ controllers. IEEE Trans. Autom. Control 44(1), 208-213 (1999)

57. Samko, S., Kilbas, A., Marichev, O.: Fractional Integrals and Derivatives: Theory and Applications. Gordon and Breach Science Publishers, Amsterdam (1993)

58. Say, J.B.: Traité dÉconomie Politique (translated as A Treatise on Political Economy). Batoche Books, Kither, Paris $(1803,17,19,26,41(2001))$
59. Senani, R.: On the realization of floating active elements. IEEE Trans. Circuits Syst. 33(3), 323-324 (1986)

60. Seymour, M. (ed.): Dynamic Factors in Industrial Productivity. Basil Blackwell, Oxford (1956)

61. Shakespeare, W.: As You Like It (Act 2, Scene 7). Cambridge University Press, New York ([1599] 2000)

62. Soliman, A.M., Saad, R.A.: Two new families of floating fdnr circuits. J. Electr. Comput. Eng. 2010(Article ID 563761), 7 p (2010)

63. Stiglitz, J.E.: Information and the change in the paradigm in economics. Am. Econ. Rev. 92(3), 460-501 (2002)

64. Strukov, D.B., Snider, G.S., Stewart, D.R., Williams, R.S.: The missing memristor found. Nature 97, 80-83 (2008)

65. Tarasov, V.: Fractional Dynamics: Applications of Fractional Calculus to Dynamics of Particles, Fields and Media. Springer, New York (2010)

66. Temin, P.: General equilibrium models in economic history. J. Econ. Hist. 31(1), 58-75 (1971)

67. Thoma, J., Bouamama, B.O.: Modelling and Simulation in Thermal and Chemical Engineering: A Bond Graph Approach. Springer, Berlin (2010)

68. Thoma, J.U.: Introduction to Bond Graphs and Their Applications. Pergamon Press, Oxford (1975)

69. Tsai, J.J.H., Gero, J.S.: Unified Energy-Based Qualitative Representation for Building Analysis. VDM Verlag, Saarbrucken (2009)

70. Tsai, J.J.H., Gero, J.S.: A qualitative energy-based unified representation for buildings. Autom. Constr. 19(1), 20-42 (2010)

71. Valério, D., da Costa, J.S.: An Introduction to Fractional Control. IET, Stevenage (2012)

72. Ventra, M.D., Pershin, Y.V., Chua, L.O.: Circuits elements with memory: memristors, memcapacitors and meminductors. Proc. IEEE 97(10), 1717-1724 (2009)

73. Walras, L.: Elements dÉconomie Politique Pure (translated to Elements of Pure Economics). Homewwod, Irwin (1874, 1877 (1954))

74. Wellstead, P.E.: Introduction to Physical System Modelling. Academic Press, London (1979)

75. Williams, R.S.: How we found the missing memristor. IEEE Spectr. 45(12), 28-35 (2008)

76. Wong, Y.K.: Application of bond graph models to economics. Int. J. Model. Simul. 21(3), 181-190 (2001) 